OPEN ACCESS

Edited by:

Umesh S. Deshmukh, Oklahoma Medical Research

Foundation, United States

Reviewed by:

Fei Liu,

Texas A\&M University, United States Yogesh M. Scindia,

University of Florida, United States

*Correspondence:

Hua-feng Liu

liuhf@gdmu.edu.cn

Qingjun Pan

pqj@gdmu.edu.cn

tThese authors have contributed equally to this work

Specialty section:

This article was submitted to Autoimmune and Autoinflammatory

Disorders,

a section of the journal

Frontiers in Immunology

Received: 21 June 2021 Accepted: 14 September 2021 Published: 30 September 2021

Citation:

Li A, Guo F, Pan Q, Chen S, Chen J, Liu H-f and Pan Q (2021) Mesenchymal Stem Cell Therapy: Hope for Patients With Systemic Lupus Erythematosus.

Front. Immunol. 12:728190. doi: 10.3389/fimmu.2021.728190

\section{Mesenchymal Stem Cell Therapy: Hope for Patients With Systemic Lupus Erythematosus}

\author{
Aifen $\mathrm{Li}^{\dagger}$, Fengbiao Guo ${ }^{\dagger}$, Quanren Pan, Shuxian Chen, Jiaxuan Chen, \\ Hua-feng Liu* and Qingjun Pan* \\ Key Laboratory of Prevention and Management of Chronic Kidney Disease of Zhanjiang City, Institute of Nephrology, \\ Affiliated Hospital of Guangdong Medical University, Zhanjiang, China
}

Systemic lupus erythematosus (SLE) is a chronic autoimmune disease. Although previous studies have demonstrated that SLE is related to the imbalance of cells in the immune system, including B cells, T cells, and dendritic cells, etc., the mechanisms underlying SLE pathogenesis remain unclear. Therefore, effective and low side-effect therapies for SLE are lacking. Recently, mesenchymal stem cell (MSC) therapy for autoimmune diseases, particularly SLE, has gained increasing attention. This therapy can improve the signs and symptoms of refractory SLE by promoting the proliferation of Th2 and Treg cells and inhibiting the activity of Th1, Th17, and B cells, etc. However, MSC therapy is also reported ineffective in some patients with SLE, which may be related to MSC- or patientderived factors. Therefore, the therapeutic effects of MSCs should be further confirmed. This review summarizes the status of MSC therapy in refractory SLE treatment and potential reasons for the ineffectiveness of MSC therapy from three perspectives. We propose various MSC modification methods that may be beneficial in enhancing the immunosuppression of MSCs in SLE. However, their safety and protective effects in patients with SLE still need to be confirmed by further experimental and clinical evidence.

Keywords: systemic lupus erythematosus, mesenchymal stem cells, immunomodulation, transplantation, inefficacy, modification

\section{SLE TREATMENT HAS A LONG WAY TO GO}

Systemic lupus erythematosus (SLE) is an autoimmune disease that exhibits high population heterogeneity, with women of childbearing age being the most highly affected population. The pathogenesis of SLE remains unclear. Previous studies showed that abnormal activation of immune cells, such as B cells (1), T cells (2), macrophages (3), basophils (4) and dendritic cells (DCs) (5), etc., played a crucial role in SLE. These activated immune cells also contributed to the production of proinflammatory factors and pathogenic autoantibodies, causing the deposition of immune complexes in tissues and inducing multiple organ damage. SLE is difficult to diagnose in the early stages because the symptoms and signs are not typical. Currently, the classic methods for SLE treatment are corticosteroids and immunosuppressors, which chronically prolong the disease course and mostly exhibit chronic remission-relapse, whereas a few patients achieve long-term remission (6). Importantly, immunosuppressive therapies fail to prevent disease relapse in more than half of the 
patients, and high-dose treatment may even increase the risk of severe infection and death (7). Additionally, most patients exhibit damage to the kidneys or other organs, partly limiting the application of immunosuppressive therapy. Hence, the development of new drugs and therapies is urgently needed (8) and especially the biological agents have gained the attention of researchers. In the past 60 years, belimumab has been the only biological agent approved by the US FDA for SLE treatment; however, this agent utilizes a single target and cannot inhibit plasma cells and switched memory B cells (9). Also, other biological agents, such as tabalumab, do not significantly improve the disease conditions and even have adverse side effects in patients with SLE (10).

Lymphopenia or leukopenia has been reported in patients with autoimmune diseases, such as SLE (11). Therefore, autologous hematopoietic stem cell (HSC) transplantation performed for SLE treatment (12). However, it was demonstrated that this therapy had high transplant-related mortality and relapse (13), possibly because of defects in the bone marrow stem cells and abnormal immune function in patients with SLE (14). Later, it was revealed that both genetic and inflammatory factors altered the number and function of HSCs in a murine lupus model (15). Also, it has been reported that allogeneic HSC transplantation caused relapses and opportunistic infections after seven months, which did not significantly differ from the adverse effects of autologous transplantation (16). Therefore, SLE treatment remains challenging.

In the 1960s and 1970s, Friedenstein discovered a cell that could differentiate and adhere to plastic under culture conditions (17). In 1991, Caplan named these cells mesenchymal stem cells (MSCs) (18). Then, bone marrow-derived MSCs (BM-MSCs) were isolated and cultured in vitro and transferred back into patients with hematologic malignancies (19). No transplantationrelated adverse reactions were observed in this report. Autologous BM-MSCs are more accessible to obtain than allogeneic BMMSCs, and they do not induce immune rejection; thus, they were used for disease treatment (20). However, a clinical study of autologous MSC transplantation for SLE treatment revealed that autologous MSCs increased Treg cells but had no effect on disease activity and could not reduce the patient's clinical symptoms (21). Allogeneic MSC transplantation has a more extensive therapeutic range and therapeutic potential than autologous transplantation. This approach is widely used to treat various diseases, including graft versus host disease (GVHD), osteoarthritis, and asthma, and in the regeneration and repair of damaged tissues (22). Therefore, research on MSCs has shifted from basic research to clinical applications, particularly in SLE, as shown in Figure $\mathbf{1}$.

MSCs can also be successfully isolated from the umbilical cord tissues and placenta, and the properties and functions of these MSCs were similar to BM-MSCs; however, compared with BM-MSCs, these cells exhibited lower immunogenicity and more vigorous proliferation and differentiation abilities $(23,24)$. Subsequently, several allogeneic MSC transplantation for patients with active and refractory SLE were carried out (25-27). A series of results have been obtained that the doses of immunosuppressive drugs used in patients with SLE reduced, and the mortality rate significantly decreased. However, MSC therapy for SLE is currently in the clinical stage. Although most clinical studies have confirmed that MSCs are effective for SLE treatment, many challenges remain to overcome before clinical application.

\section{MOLECULAR MECHANISMS OF MSCS IN SLE}

\section{MSCs Regulate Adaptive Immune Cells}

The immunosuppressive effect of MSCs is essential for MSC therapy. MSCs can express prostaglandin E2 (PGE2) (28), transforming growth factor-beta (TGF- $\beta$ ) (29), nitric oxide (NO) (30), C-C motif chemokine ligand 2 (CCL2) (31), indoleamine-pyrrole 2,3-dioxygenase (IDO) (32), interleukin-10 (IL-10) (29, 33), and programmed cell death-1 ligands (PD-L1 and PD-L2) (34). Transplanted MSCs can act on tissues or organs through cell-to-cell contact, secrete cytokines and extracellular vesicles (EVs), which further inhibit the production of proinflammatory cytokines, and exert immunosuppressive effects, as shown in Figure 2 (35-37).

Abnormally activated B cells in patients with SLE exert multiple functions, such as producing large quantities of autoantibody (e.g., anti-dsDNA and ANA), secreting proinflammatory cytokines (e.g., IL-6 and IFN- $\gamma$ ), and antiinflammatory cytokines (e.g., IL-10 and TGF- $\beta$ ) (1). MSCs could inhibit B cells differentiation into plasma cells and antibody production via soluble factors and cell-to-cell contact involving the $\mathrm{PD}-1 / \mathrm{PD}$ ligand pathway $(35,36)$. Regulatory $\mathrm{B}$ cells (Bregs) exert immunosuppressive functions at least partly through the production of IL-10 and TGF- $\beta$ in SLE $(38,39)$. MSCs can induce the expansion of Bregs and inhibit excessive inflammatory responses in a murine lupus model (33). Currently, whether MSCs could affect the expression of B cell co-stimulatory molecules and cytokine production is unknown.

Abnormal activation of T cells, imbalance of Th1/Th2, and other cell subsets are generally involved in the pathogenesis of SLE. The serum IL-17 from patients with SLE were significantly higher than healthy controls, which positively correlated with the SLEDAI score (40). It has been widely reported that $\mathrm{T}$ follicular helper (Tfh) cells could help B cells produce autoantibodies and form immune complexes, which caused tissue and organ damage, and eventually aggravated the condition of SLE patients (2). MSCs inhibited the differentiation of naïve $\mathrm{CD}^{+} \mathrm{T}$ cells into $\mathrm{Tfh}$ cells through cell-to-cell contact and the activation of iNOS, decreased the production of IL-21, alleviated lupus nephritis, and prolonged the survival rate of lupus-prone mice $(30,41)$. Similarly, Th1/ Th2 subgroups in patients with SLE were unbalanced (biased toward Th1) and released pro-inflammatory cytokines; they have been considered important for disease and promote SLE progression (42). Additionally, studies have shown that MSCs could inhibit $\mathrm{T}$ cell activation in a dose-dependent manner; inhibit the differentiation of $\mathrm{CD}^{+}{ }^{+} \mathrm{T}$ cells into Th1, Th17, and Tfh cells; promote Treg proliferation and secretion of IL-10, reduce the ratio of $\mathrm{Th} 1 / \mathrm{Th} 2$; and restore the proportion of 


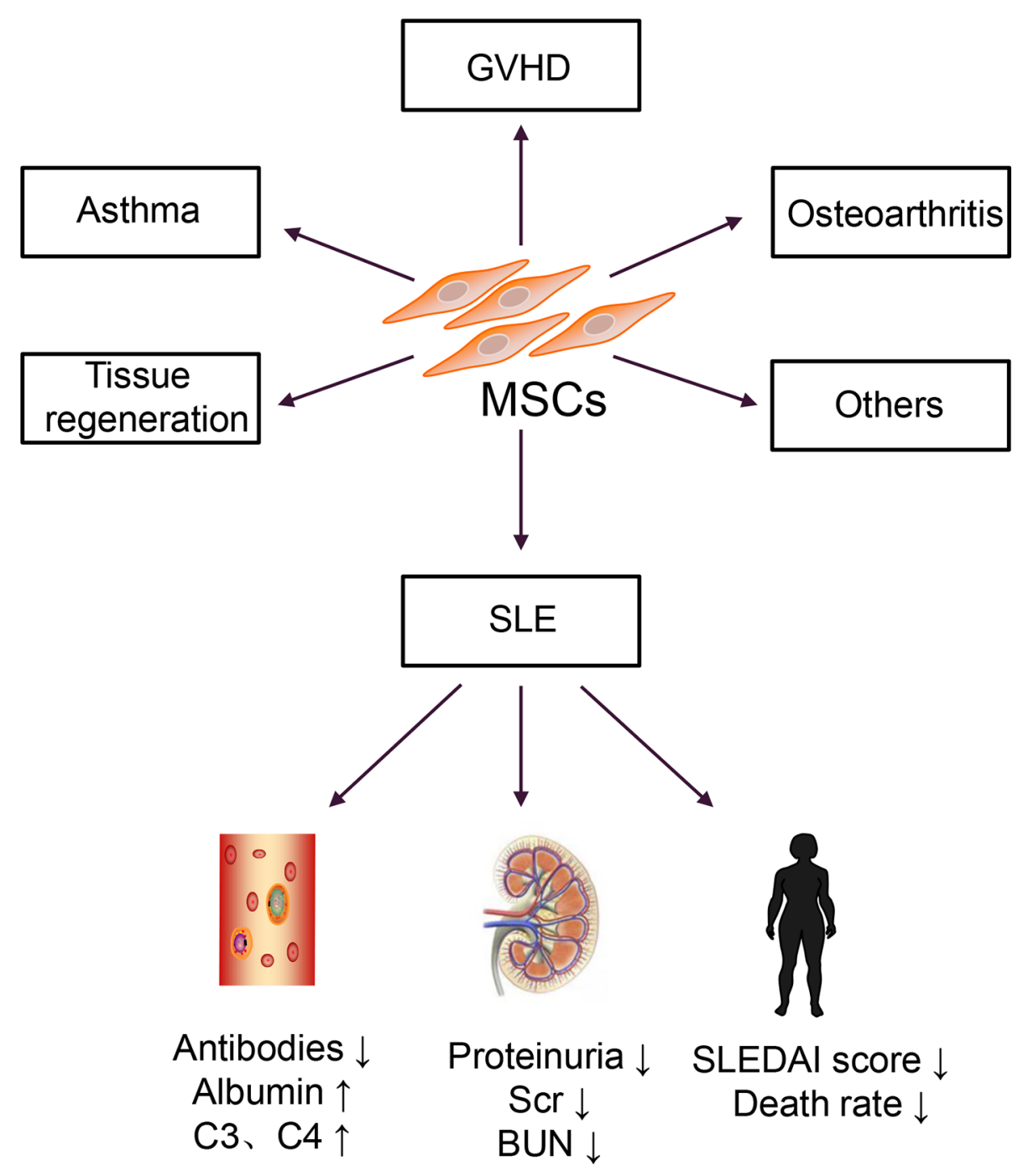

FIGURE 1 | Clinical applications of MSCs.

Treg/Tfh cells, thereby correcting the abnormally activated $\mathrm{T}$ cells and cell subsets in patients with $\operatorname{SLE}(41,43)$. In addition, it is reported that after treating thirty refractory SLE patients with human umbilical cord-MSCs for three months, the Treg subgroups and the levels of TGF- $\beta$ in the peripheral blood were increased (40). In contrast, the expression levels of Th17 cells and IL-17, tumor necrosis factor (TNF- $\alpha$ ), and other proinflammatory factors were significantly decreased (40). They further co-cultured human umbilical cord-MSCs with peripheral blood mononuclear cells from SLE patients and found that MSCs could upregulate the expression of TGF- $\beta$ and Treg cells in a dose-dependent manner in vitro (40). Researchers also employed a combination of MSCs with five SLE clinical drugs, viz., prednisone, dexamethasone, cyclosporin A, mycophenolate mofetil, and rapamycin, in animal experiments. These drugs could improve the therapeutic effect of MSCs, thereby enhancing the functions of Treg and alleviating the drug cytotoxicity (44).

\section{MSCs Regulate Innate Immune Cells}

The innate immune response is the first line of defense against viral invasion in vivo. Recent studies have revealed that the innate immune response plays a vital role in SLE progression by initiating and maintaining an adaptive immune response.

Macrophages have two functional states, often exhibited pro(M1) as well as anti-inflammatory (M2) properties (45). In SLE, macrophages have the defective phagocytic ability and are abnormally activated, promoting disease progression (3). When co-cultured with macrophages, MSCs exerted an immunomodulatory effect by upregulating anti-inflammatory and downregulating pro-inflammatory molecules of macrophages in a murine lupus model (46). Except for regulating macrophage 


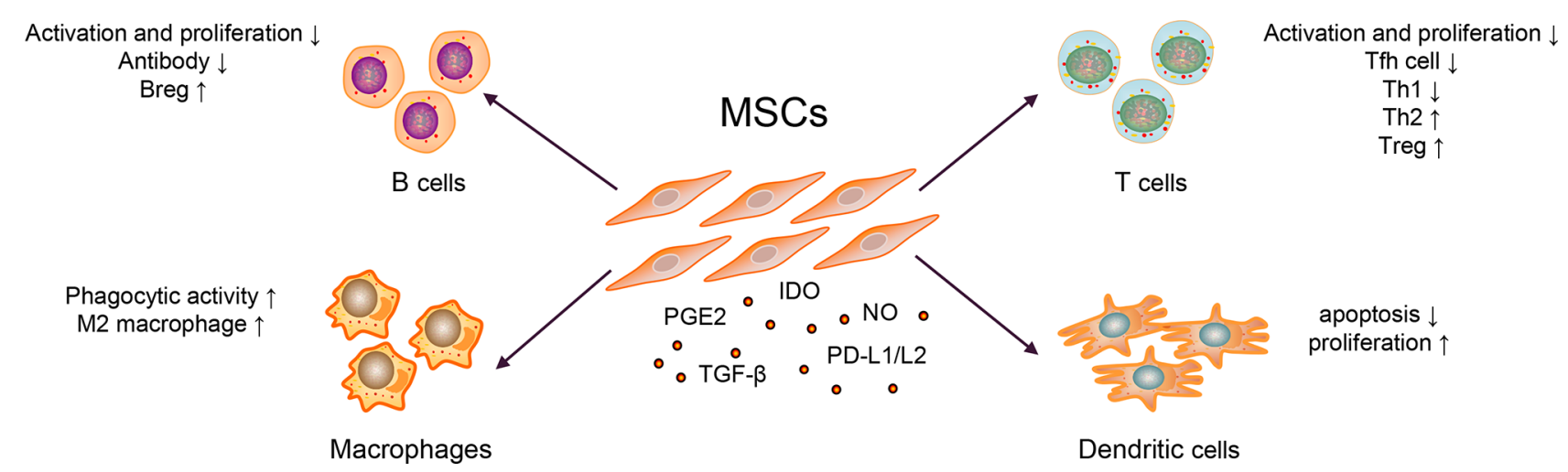

FIGURE 2 | Mechanisms of MSC Therapy in SLE.

polarization, the study also revealed that MSCs could enhance the phagocytic activity of macrophages, thereby alleviating disease activity in a murine model $(46,47)$. In other diseases, such as leukemia, MSCs could also help host macrophages to repair the damaged bone marrow microenvironment by reprogramming macrophages (48).

DCs play a critical role in activating $\mathrm{T}$ cells and B cells $(5,49)$. Two types of DC subsets have been identified in Homo sapiens: myeloid DCs and plasmacytoid DCs (50). In the pathogenesis of SLE, plasmacytoid DCs were considered the primary source of type I interferon (IFN), which promoted the activation of T and B cells (51). Similarly, co-stimulatory molecules overexpressed by myeloid DCs could accelerate $\mathrm{T}$ cell maturation, promote $\mathrm{T}$ cells differentiation into pro-inflammatory cells and lead to organ damage in vitro (5). It confirmed that MSCs could inhibit the maturation and function of DCs and reduced the expression of presentation molecules, such as human leukocyte antigen-DR and co-stimulatory molecules, such as CD80 and CD86 (52). MSCs could also induce the production of regulatory DC (DCregs) and escaped apoptosis, further enhancing phagocytosis's ability and inhibiting T cells' activation and proliferation $(53,54)$. In addition, MSCs inhibited the secretion of TNF- $\alpha$ by DCs and upregulated the secretion of IL-10 (55). But these mechanisms are known little in SLE. As DCs is essential for the pathogenesis of SLE, these functions of MSCs need to be confirmed in murine model or patients with SLE. Later, it was revealed that the numbers of tolerogenic CD1c ${ }^{+}$DCs in the peripheral blood and the levels of serum FLT3L in patients with SLE significantly decreased (56). After transplanting of umbilical cord-MSCs, the significantly upregulated levels of FLT3L promoted the proliferation and inhibited the apoptosis of tolerogenic $\mathrm{CD} 1 \mathrm{c}^{+} \mathrm{DCs}$, thereby improving the condition of lupus (56). In SLE, the activity of myeloid-derived suppressor cells impaired in both murine and humans (57) could promote Th17 cells and Treg differentiation and shift the ratio of Th17/Treg, thereby promoting the progression of SLE (58). MSC infusion could restore the activity of myeloid-derived suppressor cells in inflammatory and autoimmune diseases, such as Sjögren syndrome $(28,59)$; however, it remains unclear in SLE.

\section{CURRENT STATUS AND CHALLENGES OF THE APPLICATION OF MSCS IN SLE}

There are currently thirteen clinical studies on the treatment of SLE with MSCs registered at www.clinicaltrials.gov, among which nine have completed, and four are in progress. Many studies suggested that MSC transplantation could effectively improve the clinical symptoms of active and refractory SLE patients; reduce the SLEDAI score; decrease the levels of proteinuria, autoantibodies, and complements; and reverse multiple organ damage $(26,60)$.

A meta-analysis on MSC therapy in a murine lupus nephritis model was conducted from October 2009 to October 2020 and revealed that MSC therapy increased the levels of serum albumin and reduced the levels of dsDNA and proteinuria (61). Moreover, MSCs could reduce the levels of IL-2, IL-12, IL-17, IFN- $\gamma$ and improve the renal sclerosis score (61). Also, allogeneic MSC transplantation was used for fifteen patients with active and refractory SLE and followed up for $17.2 \pm 9.5$ months (25). No severe toxicities or adverse events were reported (25). All patients attained disease remission, and the SLEDAI score, anti-dsDNA levels, and $24 \mathrm{~h}$ proteinuria levels markedly decreased within one year. One year later, two patients experienced a relapse of proteinuria (25). This approach was a good starting point for MSC therapy of SLE. Subsequently, a six-year follow-up observation of allogeneic MSC transplantation for refractory SLE found that all patients tolerated the treatment well, with no increase in the risk of tumor formation or infection (27). Furthermore, MSC therapy decreased the SLEDAI score, the levels of autoantibodies, proteinuria and increased serum albumin levels (62). The latest long-term retrospective study reported that MSC transplantation-related mortality was only $0.2 \%$, confirming the effectiveness and safety of MSC transplantation (63). To date, MSC therapy was the most promising treatment for SLE, particularly for patients who do not respond well to traditional therapies.

Although most studies indicated that MSC transplantation could improve the disease condition of patients with SLE, a few have shown that MSC therapy was ineffective. It was worth 
noting that no severe adverse effects were observed after autologous BM-MSC transplantation. Although BM-MSCs increased the numbers of $\mathrm{CD} 4{ }^{+} \mathrm{CD} 25^{+} \mathrm{FoxP} 3^{+}$cells, they did not improve disease conditions, even in young patients $(21,64)$. Murine BM-MSCs inhibited the deposition of immune complex in the glomerulus and restrained lymphocytic infiltration and glomerular proliferation in lupus animal models (36). However, they did not affect the production of anti-dsDNA or proteinuria (36). In addition, based on standard immunosuppressive therapy, twenty-five patients with SLE were recruited to treat with human umbilical cord MSCs (dose $2 \times 10^{8}$ cells/person) in 2012 (NCT01539902) (65). However, the clinical study was terminated after treating eighteen patients and revealed that the levels of proteinuria, serum albumin, complement, SLEDAI score, and renal function in the MSC therapy group had no significant difference compared to the placebo group (65). However, the authors did not provide specific reasons for this failure. Hence, the therapeutic effects of MSCs must be confirmed in large-scale clinical studies.

Notably, intravenous infusion of MSCs is complicated and may have serious side effects, such as vascular occlusion and the induction of tumor formation. Considering the safety of MSC transplantation, many investigators have focused on EVs derived from MSCs. Compared with MSCs, EVs derived from MSCs exhibited similar immunosuppressive functions in several studies in vitro as cell-free therapy and showed high safety $(66,67)$. However, there is currently no standard and high-efficiency extraction method for EVs, which leads to low production yields and increased heterogeneity of MSC EVs (68). Notably, EVs derived from MSCs have not been used in clinical studies of SLE.

\section{POTENTIAL CAUSES OF MSC THERAPY INEFFICACY IN SLE TREATMENT}

In the past few decades, there have been successes and failures in using MSCs to treat SLE. There is no evidence that MSCs are unsafe or promote the progression of SLE. However, reports showed that MSCs could secrete cytokines with strong proinflammatory effects, such as IL-6 $(69,70)$, which might be related to some controversy in their application. Also, MSCs are susceptible to aging due to the influence of the surrounding environment (71). The etiology and pathogenesis of SLE are still unclear. The microenvironment of patients with SLE is complicated, causing the therapeutic effects of intravenously infused MSCs can be influenced by many factors. We summarize the potential causes of MSC therapy inefficacy in SLE from the following aspects: the defective BM-MSCs in patients with SLE, the expansion of MSCs in vitro, and the complex microenvironment in patients with SLE. It is worth noting that studies in many other diseases have confirmed that most intravenously infused MSCs could be trapped and cleared in the lung (72-74), which may be one of the reasons for MSC therapy inefficacy.

\section{Defective BM-MSCs in Patients With SLE}

SLE is an autoimmune disease that is genetically inherited, with patients showing disease-related susceptibility genes $(75,76)$. It is well known that long-term use of high doses of immunosuppressive agents could increase the risk of bone marrow suppression in patients, which aggravated complications such as infection and anemia. MSCs from the bone marrow of patients with SLE were defective (14). Hence, SLE is considered a type of stem cell-mediated disease, resulting in weakened HSCs growth and differentiation $(14,77)$. The morphology of BM-MSCs in patients with SLE was similar to that of healthy controls, and both exhibited the typical immunophenotype, positive for CD44, CD73, and CD105, and negative for CD34, CD19, CD45, and other hematopoietic cell indicators; however, BM-MSCs from patients with SLE exhibited proliferation, differentiation, migration, and homing ability defects and are more prone to senescence and apoptosis (14). Moreover, their ability to secrete cytokines is weakened, causing a decrease in the inhibitory effect on $\mathrm{T}$ and $\mathrm{B}$ cells and other immune cells, thereby promoting the progression of $\operatorname{SLE}(71,77)$. In addition, BM-MSCs are affected by age. As donors grow older, BM-MSCs tend to senescence, and their functions gradually weaken, resulting in poor effects after transplantation (77).

If combined transplantation of MSCs and HSCs, MSCs could promote the transplantation of HSCs, enhance hematopoietic function, and improved GVDH condition in vivo (78). This finding indicates that MSCs have potent roles in promoting body repair while exerting immunosuppressive effects. However, it is unknown whether MSCs transplanted into the body could promote the recovery of BM-MSC function in SLE. Additional clinical data are required to confirm these findings. If appropriate methods are used to modify the BM-MSCs of patients with SLE in vitro and then re-inject them into the body, the function of autologous defective MSCs in these patients is expected to be restored.

\section{Effect of In Vitro Expansion of MSCs}

A murine model showed when the generation of MSCs expanded in vitro is low, the cells possess a stronger ability to home to damaged tissues (79). However, the morphology and function of younger MSCs are unstable, resulting in unknown effects. When the number of MSCs is lower, fewer cells can be used for transplantation. And a low number of MSCs could promote lymphocyte proliferation while a larger dose always has an inhibitory effect on lymphocyte proliferation (80). Therefore, to achieve the best therapeutic effect, MSCs must be cultured in vitro to obtain sufficient cells.

However, there is currently no standardized system for the isolation, culture, and expansion of MSCs. When MSCs are cultured and expanded in vitro, gene mutations may occur because of the culture system and conditions used, resulting in expansion-related senescence, weakened proliferation and differentiation ability, reduced adhesion, and homing ability (81). Also, if MSCs are expanded in vitro for a long time, they could gradually lose the ability to recognize endogenous tissues and exhibit weakened genetic stability (82); therefore, when these 
cells are transplanted into the body, their therapeutic effect may decrease, or they may pose a safety risk.

\section{Complex Microenvironment in Patients With SLE}

MSCs were mostly trapped in the lungs when injected intravenously into the body (83) and could not be detected after 7-14 days [65]. However, due to the different microenvironments of patients with SLE, the residence time and efficacy of MSCs differ; when harmful factors damaged local tissues, the residence time of MSCs in vivo could be extended, promoting the repair of damaged tissues (84). In addition, high-level inflammatory factors could enhance the immunosuppressive effect of MSCs on immune cells by simulating the inflammatory microenvironment of patients in vitro (85).

Evidence showed an imbalance in Th1/Th2 and other cell subpopulations in patients with SLE, which significantly increased the levels of the pro-inflammatory cytokines IL-6, TNF- $\alpha$, and IL- $1 \beta$ (86). IL-6 and IL- $1 \beta$ were known to drive Th17 differentiation and promote the levels of serum IL-21 and IL-17 which correlated with disease activity $(87,88)$. When MSCs exposed to IL-6, the stemness of MSCs was enhanced through an ERK1/2-dependent mechanism (89); however, whether IL- 6 could reduce the immunosuppressive function of MSCs still unclear. Therefore, it needs to further investigate the specific effect of IL- 6 on MSCs. In patients with SLE, high concentrations of serum TNF- $\alpha$ could significantly inhibit the migration and homing capacity of SLE BM-MSCs via TNF receptor I (90). Also, anti-TNF therapies for rheumatic diseases led to the formation of anti-dsDNA and druginduced lupus (91). In addition, the upregulation of renal TNF- $\alpha$ was considered to play a vital role in the activation of local inflammation and formation of tissue damage (92); however, in collagen-induced arthritis, when TNF- $\alpha$ was present in large quantities, increasing the number of MSCs does not relieve the clinical symptoms (93). When costimulated with TNF- $\alpha$ and IL- $1 \beta$, MSCs exhibited proinflammatory effects and promoted $\mathrm{T}$ cell proliferation and differentiation (94). In summary, the inflammatory environment may induce MSCs to exert pro-inflammatory effects, leading to the failure of MSC therapy in autoimmune diseases, including SLE.

MSCs can secrete anti-inflammatory cytokines such as indoleamine-pyrrole 2,3-dioxygenase and prostaglandin E2, as well as pro-inflammatory cytokines such as IL- 6 and TNF- $\alpha$ (69), which may accelerate disease progression. Another study revealed that IL-6 silencing could weaken the inhibition of the proliferation of activated T cells (95). Therefore, MSCs may have dual effects on the disease.

\section{NOVEL MECHANISMS AND DIRECTIONS OF MSCS IN SLE TREATMENT}

MSCs have strong immunomodulatory plasticity and could be easily influenced by the microenvironment, which is among the reasons why MSC therapy is ineffective. Thus, MSC modifications, such as genetic and preconditioning modifications, could avoid the influence of the environment. The former alters MSCs by inserting a gene, whereas the latter alters MSCs using chemical and/or physical factors in vivo, thereby overexpressing specific genes and improving the efficacy of disease treatment. Modified MSCs are now widely used to treat tumors, cardiovascular diseases, neurological diseases, bone, and joint diseases, and so on (96).

Pro-inflammatory cytokines contribute to the pathogenesis of SLE; however, for MSCs, strong inflammatory cytokines were effective attractors that could activate the immunesuppressive function, whereas low levels of inflammatory factors could reduce the immune-suppressive role or even trigger the immune system $(97,98)$. In a murine model, transplanted IL-37 overexpressed MSCs inhibited the inflammatory microenvironment in vivo, prolonged survival, and reduced SLE-like symptoms (99). Similarly, pretreated MSCs with media containing pro- or anti-inflammatory cytokines or related molecules such as poly (I:C) and glucocorticoids could enhance the immunosuppression of MSCs (100-102). Pretreated MSCs with IFN- $\gamma$ could increase IDO (32) and significantly inhibited splenic B cells' proliferation and the production of antibodies (103). The pretreatment of MSCs with IL- $1 \beta$ significantly increased the number of Treg and Th2 cells and decreased Th1 and Th17 cells (104). Besides, if IFN- $\gamma$ co-cultured with any of the three other pro-inflammatory cytokines, viz., TNF- $\alpha$, IL- $1 \alpha$, and IL$1 \beta$, the adhesion, migration, and homing abilities of MSCs could be enhanced (105). Modified MSCs with IL-10 could inhibit tumor growth by reducing the production of IL-6 (106). These results indicate that MSC modification could enhance the immunosuppression of MSCs, providing a new and feasible direction for SLE therapy.

The aging phenotype of MSCs could be wholly or partially reversed by inhibiting MSC senescence-related genes, which improves the immune regulation function in vitro (107, 108). Recently, several studies demonstrated that the pretreatment of MSCs with rapamycin and Dickkopf-1 reversed the senescence of MSCs and improved the immune regulation of MSCs (108-110). There are also other ways to modify MSCs and reverse senescence phenotype, such as pretreated MSCs with hypoxia or by upregulating the expression of CBX4 or Erb-B2 receptor tyrosine kinase 4 (ERBB4), which could change the senescence phenotype, reduce the expression of senescence-associated $\beta$-gal, and maintain the stemness of MSCs (107, 111-113). In contrast, upregulated CD146, CD264, SIRT3, and TLR3 expression levels in MSCs increase senescence (114-117). MSC senescence is unavoidable in SLE treatment. If the senescence phenotype of MSCs is modified by various methods, the function of MSCs can be improved, thereby enhancing their therapeutic ability.

Several studies have revealed that increased the expression of homing molecules and cell surface receptors, such as CC chemokine receptors 1 (CCR1) (118), C-C motif chemokine 
ligand 2 (CCL2) (31), C-X-C motif chemokine receptors 2 (CXCR2) (119), CXCR4 (120) by modifying MSCs could promote the therapeutics of MSCs.

However, it is controversial whether the migration and homing of MSCs to damaged tissues are required for their immunomodulation effects. For the local immune response of MSCs, the therapeutics of MSCs may be associated with its migration and homing abilities. It has been reported that the overexpression of CCR1, CXCR2, and CXCR4 in MSCs or modified MSCs with biomimetic extracellular matrices and poly (dimethylsiloxane) could stimulate more MSCs to migrate to the lesion sites, secrete more anti-inflammatory cytokines, and accelerate tissue healing (118-122). The pretreatment of MSCs with miR-9-5p or TNF- $\alpha$ could also improve the migration ability of MSCs, whereas the inhibition of miR-9-5p reduced MSC migration $(123,124)$. For the systemic immune responses of MSCs, many studies observed the phenomenon that most of the MSCs were trapped in the lung after IV infusion in murine models (72-74). For the mechanisms, the MSCs trapped in the lung after IV infusion may secret bioactive molecules and EVs into the blood and efficiently regulate systemic immune responses $(125,126)$. For example, MSCs trapped in the lung with higher expression of the gene for a multifunctional antiinflammatory protein tumor necrosis factor- $\alpha$ stimulated gene/ protein 6 (TSG-6) could efficiently regulate systemic immune responses in lung injury mice (125). Meanwhile, the overexpression of CCL2 in MSCs from patients with SLE could improve MSC immunoregulatory abilities both in vitro and in vivo, whereas the knockdown of CCL2 from normal MSCs led to a weakened immunoregulatory power (31). This may also correlate to the bioactive molecules secreted by MSCs. However, the specific molecular mechanisms of these bioactive molecules and EVs regulating the systemic immune responses need further studies.

Studies showed the immunomodulatory of MSCs is partly the result of EVs, which play an increasingly important role in MSC therapy $(127,128)$. As a novel cell-free therapy, EVs could deliver specific molecules to target tissues or organs and exhibit nearly the same immunomodulation ability as MSCs $(128,129)$. EVs derived from modified MSCs are widely used in several diseases in vitro $(37,127-129)$. Exosomes derived from miR-122modified MSCs could improve the sensitivity of tumor cells to drugs and increase the effect of drugs on cancer treatment (127). In the rat models of spinal cord injury, exosomes derived from miR-126-modified MSCs could promote the recovery of injury volume and trigger the regeneration of axons (128). Moreover, exosomes from Akt-modified MSCs in the acute myocardial infarction rat models could reduce myocardial cell apoptosis, increase cardiac regeneration, and improve cardiac function (129). In rheumatoid arthritis (RA) murine model, exosomes derived from miR-150-5p modified MSCs could decrease the regeneration of synoviocytes and reduce joint destruction, thereby being the potential treatment for RA (37). However, EVs derived from MSCs remains limited in murine models and patients with SLE.

\section{FUTURE PERSPECTIVES}

MSCs are currently used to treat patients with active and refractory SLE, and a series of promising results have been obtained. However, MSCs do not always exhibit strong immunosuppressive function and may lose their therapeutic effect under the influence of many factors. This may occur for the following reasons: defects of BM-MSCs in patients with SLE, the impact of MSCs culture in vitro, and the complex microenvironment of patients with SLE. To maximize the therapeutic effects of MSCs or EVs derived from MSCs in vivo, MSCs need to be pretreated by various means, including proand anti-inflammatory cytokines, improving their senescence and enhancing their migration and homing ability.

However, MSC modification must also be confirmed to determine whether MSC gene mutation will occur or if the transplantation of MSCs will harm the body in the long term, including serious problems such as tumorigenesis and teratogenesis. No studies have focused on whether the modification of MSCs alters their safety. In the long term, MSC modification may improve the therapeutic effects of MSCs in autoimmune diseases, particularly in SLE.

MSCs are in the early stages of clinical application and are typically combined with hormonotherapy. Whether hormone therapy can be discontinued using modified MSCs should be examined. In addition, MSC therapy improves but does not completely cure SLE. Thus, whether modified MSCs can cure SLE requires further analysis. Limited by their high cost, safety concerns, and lower SLEDAI scores of disease conditions, MSCs are rarely used in patients with mild SLE. However, comprehensive studies of MSCs and improvements in their preparation process can reduce costs and significantly expand the application of MSCs. MSCs may be more effective in patients with mild SLE or preempted for those with a genetic background of SLE, which may relieve these patients' conditions.

\section{AUTHOR CONTRIBUTIONS}

$\mathrm{AL}, \mathrm{FG}$ and QRP wrote the manuscript and designed the figures. SC, JC, and H-FL revised the manuscript. All authors contributed to the article and approved the submitted version.

\section{FUNDING}

This study was supported by National Natural Science Foundation of China (no.82070757), the Project of "Dengfeng Plan" and Department of established positions for the Zhujiang Scholar from Guangdong Medical University, and Guangdong Basic and Applied Basic Research Foundation (no.2019A1515012203), the Zhanjiang City Program for Tackling Key Problems in Science and Technology (no. 2019B01179). 


\section{REFERENCES}

1. Karrar S, Cunninghame Graham DS. Abnormal B Cell Development in Systemic Lupus Erythematosus: What the Genetics Tell Us. Arthritis Rheumatol (Hoboken N.J.) (2018) 70:496-507. doi: 10.1002/art.40396

2. Blanco P, Ueno H, Schmitt N. T Follicular Helper (Tfh) Cells in Lupus: Activation and Involvement in SLE Pathogenesis. Eur J Immunol (2016) 46:281-90. doi: 10.1002/eji.201545760

3. Ma C, Xia Y, Yang Q, Zhao Y. The Contribution of Macrophages to Systemic Lupus Erythematosus. Clin Immunol (2019) 207:1-9. doi: 10.1016/j.clim.2019.06.009

4. Pan Q, Gong L, Xiao H, Feng Y, Li L, Deng Z, et al. Basophil ActivationDependent Autoantibody and Interleukin-17 Production Exacerbate Systemic Lupus Erythematosus. Front Immunol (2017) 8:348. doi: 10.3389/fimmu.2017.00348

5. Ding D, Mehta H, McCune WJ, Kaplan MJ. Aberrant Phenotype and Function of Myeloid Dendritic Cells in Systemic Lupus Erythematosus. J Immunol (Baltimore Md. 1950) (2006) 177:5878-89. doi: 10.4049/ jimmunol.177.9.5878

6. Fanouriakis A, Kostopoulou M, Alunno A, Aringer M, Bajema I, Boletis JN, et al. Update of the EULAR Recommendations for the Management of Systemic Lupus Erythematosus. Ann Rheum Dis (2019) 78:736-45. doi: 10.1136/annrheumdis-2019-215089

7. Singh JA, Hossain A, Kotb A, Wells G. Risk of Serious Infections With Immunosuppressive Drugs and Glucocorticoids for Lupus Nephritis: A Systematic Review and Network Meta-Analysis. BMC Med (2016) 14:137. doi: 10.1186/s12916-016-0673-8

8. Pan Q, Xiao H, Shi L, He Y, Cai J, Wu J, et al. IgG4 Autoantibodies Attenuate Systemic Lupus Erythematosus Progression by Suppressing Complement Consumption and Inflammatory Cytokine Production. Front Immunol (2020) 11:1047. doi: 10.3389/fimmu.2020.01047

9. Ramsköld D, Parodis I, Lakshmikanth T, Sippl N, Khademi M, Chen Y, et al. B Cell Alterations During BAFF Inhibition With Belimumab in SLE. EBioMedicine (2019) 40:517-27. doi: 10.1016/j.ebiom.2018.12.035

10. Merrill JT, van Vollenhoven RF, Buyon JP, Furie RA, Stohl W, Morgan-Cox $M$, et al. Efficacy and Safety of Subcutaneous Tabalumab, a Monoclonal Antibody to B-Cell Activating Factor, in Patients With Systemic Lupus Erythematosus: Results From ILLUMINATE-2, a 52-Week, Phase III, Multicentre, Randomised, Double-Blind, Placebo-Controlled Study. Ann Rheum Dis (2016) 75:332-40. doi: 10.1136/annrheumdis-2015-207654

11. Keeling DM, Isenberg DA. Haematological Manifestations of Systemic Lupus Erythematosus. Blood Rev (1993) 7:199-207. doi: 10.1016/0268960x(93)90006-p

12. Marmont AM, van Lint MT, Gualandi F, Bacigalupo A. Autologous Marrow Stem Cell Transplantation for Severe Systemic Lupus Erythematosus of Long Duration. Lupus (1997) 6:545-8. doi: 10.1177/096120339700600613

13. Jayne D, Passweg J, Marmont A, Farge D, Zhao X, Arnold R, et al. Autologous Stem Cell Transplantation for Systemic Lupus Erythematosus. Lupus (2004) 13:168-76. doi: 10.1191/0961203304lu525oa

14. Sun LY, Zhang HY, Feng XB, Hou YY, Lu LW, Fan LM. Abnormality of Bone Marrow-Derived Mesenchymal Stem Cells in Patients With Systemic Lupus Erythematosus. Lupus (2007) 16:121-8. doi: 10.1177/ 0961203306075793

15. Niu H, Fang G, Tang Y, Xie L, Yang H, Morel L, et al. The Function of Hematopoietic Stem Cells Is Altered by Both Genetic and Inflammatory Factors in Lupus Mice. Blood (2013) 121:1986-94. doi: 10.1182/blood-201205-433755

16. Vanikar AV, Modi PR, Patel RD, Kanodia KV, Shah VR, Trivedi VB, et al. Hematopoietic Stem Cell Transplantation in Autoimmune Diseases: The Ahmedabad Experience. Transplant Proc (2007) 39:703-8. doi: 10.1016/ j.transproceed.2007.01.070

17. Friedenstein AJ, Gorskaja JF, Kulagina NN. Fibroblast Precursors in Normal and Irradiated Mouse Hematopoietic Organs. Exp Hematol (1976) 4:267-74.

18. Caplan AI. Mesenchymal Stem Cells. J Orthop Res (1991) 9:641-50. doi: 10.1002 /jor.1100090504

19. Lazarus HM, Haynesworth SE, Gerson SL, Rosenthal NS, Caplan AI. Ex Vivo Expansion and Subsequent Infusion of Human Bone Marrow-Derived
Stromal Progenitor Cells (Mesenchymal Progenitor Cells): Implications for Therapeutic Use. Bone Marrow Transplant (1995) 16:557-64.

20. Le Blanc K, Pittenger M. Mesenchymal Stem Cells: Progress Toward Promise. Cytotherapy (2005) 7:36-45. doi: 10.1080/14653240510018118

21. Carrion F, Nova E, Ruiz C, Diaz F, Inostroza C, Rojo D, et al. Autologous Mesenchymal Stem Cell Treatment Increased T Regulatory Cells With No Effect on Disease Activity in Two Systemic Lupus Erythematosus Patients. Lupus (2010) 19:317-22. doi: 10.1177/0961203309348983

22. Fan XL, Zhang Y, Li X, Fu QL. Mechanisms Underlying the Protective Effects of Mesenchymal Stem Cell-Based Therapy. Cell Mol Life Sci CMLS (2020) 77:2771-94. doi: 10.1007/s00018-020-03454-6

23. Lu LL, Liu YJ, Yang SG, Zhao QJ, Wang X, Gong W, et al. Isolation and Characterization of Human Umbilical Cord Mesenchymal Stem Cells With Hematopoiesis-Supportive Function and Other Potentials. Haematologica (2006) 91:1017-26. doi: 10.3324/\%25x

24. Miao Z, Jin J, Chen L, Zhu J, Huang W, Zhao J, et al. Isolation of Mesenchymal Stem Cells From Human Placenta: Comparison With Human Bone Marrow Mesenchymal Stem Cells. Cell Biol Int (2006) 30:681-7. doi: 10.1016/j.cellbi.2006.03.009

25. Liang J, Zhang H, Hua B, Wang H, Lu L, Shi S, et al. Allogenic Mesenchymal Stem Cells Transplantation in Refractory Systemic Lupus Erythematosus: A Pilot Clinical Study. Ann Rheum Dis (2010) 69:1423-9. doi: 10.1136/ ard.2009.123463

26. Wang D, Zhang H, Liang J, Wang H, Hua B, Feng X, et al. A Long-Term Follow-Up Study of Allogeneic Mesenchymal Stem/Stromal Cell Transplantation in Patients With Drug-Resistant Systemic Lupus Erythematosus. Stem Cell Rep (2018) 10:933-41. doi: 10.1016/ j.stemcr.2018.01.029

27. Wang D, Niu L, Feng X, Yuan X, Zhao S, Zhang H, et al. Long-Term Safety of Umbilical Cord Mesenchymal Stem Cells Transplantation for Systemic Lupus Erythematosus: A 6-Year Follow-Up Study. Clin Exp Med (2017) 17:333-40. doi: 10.1007/s10238-016-0427-0

28. Qi J, Tang X, Li W, Chen W, Yao G, Sun L. Mesenchymal Stem Cells Inhibited the Differentiation of MDSCs via COX2/PGE2 in Experimental Sialadenitis. Stem Cell Res Ther (2020) 11:325. doi: 10.1186/s13287-02001837-x

29. Putra A, Ridwan FB, Putridewi AI, Kustiyah AR, Wirastuti K, Sadyah NAC, et al. The Role of TNF- $\alpha$ Induced MSCs on Suppressive Inflammation by Increasing TGF- $\beta$ and IL-10. Open Access Maced J Med Sci (2018) 6:177983. doi: 10.3889 /oamjms.2018.404

30. Zhang Z, Feng R, Niu L, Huang S, Deng W, Shi B, et al. Human Umbilical Cord Mesenchymal Stem Cells Inhibit T Follicular Helper Cell Expansion Through the Activation of iNOS in Lupus-Prone B6.MRL-Fas(lpr) Mice. Cell Transplant (2017) 26:1031-42. doi: 10.3727/096368917x694660

31. Che N, Li X, Zhang L, Liu R, Chen H, Gao X, et al. Impaired B Cell Inhibition by Lupus Bone Marrow Mesenchymal Stem Cells Is Caused by Reduced CCL2 Expression. J Immunol (2014) 193:5306-14. doi: 10.4049/ jimmunol.1400036

32. Kim DS, Jang IK, Lee MW, Ko YJ, Lee DH, Lee JW, et al. Enhanced Immunosuppressive Properties of Human Mesenchymal Stem Cells Primed by Interferon- $\gamma$. EBioMedicine (2018) 28:261-73. doi: 10.1016/ j.ebiom.2018.01.002

33. Park MJ, Kwok SK, Lee SH, Kim EK, Park SH, Cho ML. Adipose TissueDerived Mesenchymal Stem Cells Induce Expansion of Interleukin-10Producing Regulatory B Cells and Ameliorate Autoimmunity in a Murine Model of Systemic Lupus Erythematosus. Cell Transplant (2015) 24:236777. doi: $10.3727 / 096368914 \times 685645$

34. Davies LC, Heldring N, Kadri N, Le Blanc K. Mesenchymal Stromal Cell Secretion of Programmed Death-1 Ligands Regulates T Cell Mediated Immunosuppression. Stem Cells (Dayton Ohio) (2017) 35:766-76. doi: $10.1002 /$ stem. 2509

35. Corcione A, Benvenuto F, Ferretti E, Giunti D, Cappiello V, Cazzanti F, et al. Human Mesenchymal Stem Cells Modulate B-Cell Functions. Blood (2006) 107:367-72. doi: 10.1182/blood-2005-07-2657

36. Schena F, Gambini C, Gregorio A, Mosconi M, Reverberi D, Gattorno M, et al. Interferon- $\gamma$-Dependent Inhibition of B Cell Activation by Bone Marrow-Derived Mesenchymal Stem Cells in a Murine Model of Systemic 
Lupus Erythematosus. Arthritis Rheumatism (2010) 62:2776-86. doi: $10.1002 /$ art.27560

37. Chen Z, Wang H, Xia Y, Yan F, Lu Y. Therapeutic Potential of Mesenchymal Cell-Derived miRNA-150-5p-Expressing Exosomes in Rheumatoid Arthritis Mediated by the Modulation of MMP14 and VEGF. J Immunol (Baltimore Md.: 1950) (2018) 201:2472-82. doi: 10.4049/jimmunol.1800304

38. Abbasifard M, Kamiab Z, Hasani M, Rahnama A, Saeed-Askari P, Khorramdelazad $\mathrm{H}$. Assessing the Expression of Immunosuppressive Cytokines in the Newly Diagnosed Systemic Lupus Erythematosus Patients: A Focus on B Cells. BMC Immunol (2020) 21:58. doi: 10.1186/ s12865-020-00388-3

39. Wang T, Mei Y, Li Z. Research Progress on Regulatory B Cells in Systemic Lupus Erythematosus. BioMed Res Int (2019) 2019:7948687. doi: 10.1155/ 2019/7948687

40. Wang D, Huang S, Yuan X, Liang J, Xu R, Yao G, et al. The Regulation of the Treg/Th17 Balance by Mesenchymal Stem Cells in Human Systemic Lupus Erythematosus. Cell Mol Immunol (2017) 14:423-31. doi: 10.1038/ cmi.2015.89

41. Yang X, Yang J, Li X, Ma W, Zou H. Bone Marrow-Derived Mesenchymal Stem Cells Inhibit T Follicular Helper Cell in Lupus-Prone Mice. Lupus (2018) 27:49-59. doi: 10.1177/0961203317711013

42. Talaat RM, Mohamed SF, Bassyouni IH, Raouf AA. Th1/Th2/Th17/Treg Cytokine Imbalance in Systemic Lupus Erythematosus (SLE) Patients: Correlation With Disease Activity. Cytokine (2015) 72:146-53. doi: $10.1016 /$ j.cyto.2014.12.027

43. Luz-Crawford P, Kurte M, Bravo-Alegrí J, Contreras R, Nova-Lamperti E, Tejedor G, et al. Mesenchymal Stem Cells Generate a CD4+CD25+Foxp3+ Regulatory T Cell Population During the Differentiation Process of Th1 and Th17 Cells. Stem Cell Res Ther (2013) 4:65. doi: 10.1186/scrt216

44. Hajkova M, Hermankova B, Javorkova E, Bohacova P, Zajicova A, Holan V, et al. Mesenchymal Stem Cells Attenuate the Adverse Effects of Immunosuppressive Drugs on Distinct T Cell Subopulations. Stem Cell Rev Rep (2017) 13:104-15. doi: 10.1007/s12015-016-9703-3

45. Redka DS, Gütschow M, Grinstein S, Canton J. Differential Ability of Proinflammatory and Anti-Inflammatory Macrophages to Perform Macropinocytosis. Mol Biol Cell (2018) 29:53-65. doi: 10.1091/mbc.E1706-0419

46. Zhang Z, Niu L, Tang X, Feng R, Yao G, Chen W, et al. Mesenchymal Stem Cells Prevent Podocyte Injury in Lupus-Prone B6.MRL-Faslpr Mice via Polarizing Macrophage Into an Anti-Inflammatory Phenotype. Nephrol dialysis Transplant Off Publ Eur Dialysis Transplant Assoc - Eur Renal Assoc (2019) 34:597-605. doi: 10.1093/ndt/gfy195

47. Deng W, Chen W, Zhang Z, Huang S, Kong W, Sun Y, et al. Mesenchymal Stem Cells Promote CD206 Expression and Phagocytic Activity of Macrophages Through IL-6 in Systemic Lupus Erythematosus. Clin Immunol (2015) 161:209-16. doi: 10.1016/j.clim.2015.07.011

48. Xia C, Wang T, Cheng H, Dong Y, Weng Q, Sun G, et al. Mesenchymal Stem Cells Suppress Leukemia via Macrophage-Mediated Functional Restoration of Bone Marrow Microenvironment. Leukemia (2020) 34:2375-83. doi: 10.1038/s41375-020-0775-3

49. Wykes M, MacPherson G. Dendritic Cell-B-Cell Interaction: Dendritic Cells Provide B Cells With CD40-Independent Proliferation Signals and CD40Dependent Survival Signals. Immunology (2000) 100:1-3. doi: 10.1046/ j.1365-2567.2000.00044.x

50. Kadowaki N. The Divergence and Interplay Between pDC and $\mathrm{mDC}$ in Humans. Front Biosci (Landmark edition) (2009) 14:808-17. doi: 10.2741/ 3279

51. Elkon KB, Wiedeman A. Type I IFN System in the Development and Manifestations of SLE. Curr Opin Rheumatol (2012) 24:499-505. doi: 10.1097/BOR.0b013e3283562c3e

52. Jiang XX, Zhang Y, Liu B, Zhang SX, Wu Y, Yu XD, et al. Human Mesenchymal Stem Cells Inhibit Differentiation and Function of Monocyte-Derived Dendritic Cells. Blood (2005) 105:4120-6. doi: 10.1182/ blood-2004-02-0586

53. Zhang B, Liu R, Shi D, Liu X, Chen Y, Dou X, et al. Mesenchymal Stem Cells Induce Mature Dendritic Cells Into a Novel Jagged-2-Dependent Regulatory Dendritic Cell Population. Blood (2009) 113:46-57. doi: 10.1182/blood2008-04-154138
54. Lu Z, Chang W, Meng S, Xu X, Xie J, Guo F, et al. Mesenchymal Stem Cells Induce Dendritic Cell Immune Tolerance via Paracrine Hepatocyte Growth Factor to Alleviate Acute Lung Injury. Stem Cell Res Ther (2019) 10:372. doi: 10.1186/s13287-019-1488-2

55. Aggarwal S, Pittenger MF. Human Mesenchymal Stem Cells Modulate Allogeneic Immune Cell Responses. Blood (2005) 105:1815-22. doi: 10.1182/blood-2004-04-1559

56. Yuan X, Qin X, Wang D, Zhang Z, Tang X, Gao X, et al. Mesenchymal Stem Cell Therapy Induces FLT3L and $\mathrm{CD} 1 \mathrm{c}(+)$ Dendritic Cells in Systemic Lupus Erythematosus Patients. Nat Commun (2019) 10:2498. doi: 10.1038/ s41467-019-10491-8

57. Vlachou K, Mintzas K, Glymenaki M, Ioannou M, Papadaki G, Bertsias GK, et al. Elimination of Granulocytic Myeloid-Derived Suppressor Cells in Lupus-Prone Mice Linked to Reactive Oxygen Species-Dependent Extracellular Trap Formation. Arthritis Rheumatol (Hoboken N.J.) (2016) 68:449-61. doi: 10.1002/art.39441

58. Pang B, Zhen Y, Hu C, Ma Z, Lin S, Yi H. Myeloid-Derived Suppressor Cells Shift Th17/Treg Ratio and Promote Systemic Lupus Erythematosus Progression Through Arginase-1/miR-322-5p/TGF- $\beta$ Pathway. Clin Sci (Lond) (2020) 134:2209-22. doi: 10.1042/cs20200799

59. Tian J, Hong Y, Zhu Q, Zhou H, Zhang Y, Shen Z, et al. Mesenchymal Stem Cell Enhances the Function of MDSCs in Experimental Sjögren Syndrome. Front Immunol (2020) 11:604607. doi: 10.3389/fimmu. 2020.604607

60. Sun L, Wang D, Liang J, Zhang H, Feng X, Wang H, et al. Umbilical Cord Mesenchymal Stem Cell Transplantation in Severe and Refractory Systemic Lupus Erythematosus. Arthritis Rheumatism (2010) 62:2467-75. doi: 10.1002/art.27548

61. Zhou T, Liao C, Li HY, Lin W, Lin S, Zhong H. Efficacy of Mesenchymal Stem Cells in Animal Models of Lupus Nephritis: A Meta-Analysis. Stem Cell Res Ther (2020) 11:48. doi: 10.1186/s13287-019-1538-9

62. Wang D, Li J, Zhang Y, Zhang M, Chen J, Li X, et al. Umbilical Cord Mesenchymal Stem Cell Transplantation in Active and Refractory Systemic Lupus Erythematosus: A Multicenter Clinical Study. Arthritis Res Ther (2014) 16:R79. doi: 10.1186/ar4520

63. Liang J, Zhang H, Kong W, Deng W, Wang D, Feng X, et al. Safety Analysis in Patients With Autoimmune Disease Receiving Allogeneic Mesenchymal Stem Cells Infusion: A Long-Term Retrospective Study. Stem Cell Res Ther (2018) 9:312. doi: 10.1186/s13287-018-1053-4

64. Barbado J, Tabera S, Sánchez A, García-Sancho J. Therapeutic Potential of Allogeneic Mesenchymal Stromal Cells Transplantation for Lupus Nephritis. Lupus (2018) 27:2161-5. doi: 10.1177/0961203318804922

65. Deng D, Zhang P, Guo Y, Lim TO. A Randomised Double-Blind, PlaceboControlled Trial of Allogeneic Umbilical Cord-Derived Mesenchymal Stem Cell for Lupus Nephritis. Ann Rheum Dis (2017) 76:1436-9. doi: 10.1136/ annrheumdis-2017-211073

66. Wang JH, Liu XL, Sun JM, Yang JH, Xu DH, Yan SS. Role of Mesenchymal Stem Cell Derived Extracellular Vesicles in Autoimmunity: A Systematic Review. World J Stem Cells (2020) 12:879-96. doi: 10.4252/wjsc.v12.i8.879

67. Lai P, Weng J, Guo L, Chen X, Du X. Novel Insights Into MSC-EVs Therapy for Immune Diseases. Biomark Res (2019) 7:6. doi: 10.1186/s40364-0190156-0

68. Whitford W, Guterstam P. Exosome Manufacturing Status. Future Med Chem (2019) 11:1225-36. doi: 10.4155/fmc-2018-0417

69. Liang W, Chen X, Zhang S, Fang J, Chen M, Xu Y, et al. Mesenchymal Stem Cells as a Double-Edged Sword in Tumor Growth: Focusing on MSCDerived Cytokines. Cell Mol Biol Lett (2021) 26:3. doi: 10.1186/s11658-02000246-5

70. O'Hagan-Wong K, Nadeau S, Carrier-Leclerc A, Apablaza F, Hamdy R, Shum-Tim D, et al. Increased IL-6 Secretion by Aged Human Mesenchymal Stromal Cells Disrupts Hematopoietic Stem and Progenitor Cells' Homeostasis. Oncotarget (2016) 7:13285-96. doi: 10.18632/oncotarget.7690

71. Gao L, Bird AK, Meednu N, Dauenhauer K, Liesveld J, Anolik J, et al. Bone Marrow-Derived Mesenchymal Stem Cells From Patients With Systemic Lupus Erythematosus Have a Senescence-Associated Secretory Phenotype Mediated by a Mitochondrial Antiviral Signaling Protein-Interferon- $\beta$ Feedback Loop. Arthritis Rheumatol (Hoboken N.J.) (2017) 69:1623-35. doi: $10.1002 /$ art.40142 
72. Nose N, Nogami S, Koshino K, Chen X, Werner RA, Kashima S, et al. [18f] FDG-Labelled Stem Cell PET Imaging in Different Route of Administrations and Multiple Animal Species. Sci Rep (2021) 11:10896. doi: 10.1038/s41598021-90383-4

73. Wang X, Chen H, Zeng X, Guo W, Jin Y, Wang S, et al. Efficient Lung Cancer-Targeted Drug Delivery via a Nanoparticle/MSC System. Acta Pharm Sin B (2019) 9:167-76. doi: 10.1016/j.apsb.2018.08.006

74. Masterson CH, Tabuchi A, Hogan G, Fitzpatrick G, Kerrigan SW, Jerkic M, et al. Intra-Vital Imaging of Mesenchymal Stromal Cell Kinetics in the Pulmonary Vasculature During Infection. Sci Rep (2021) 11:5265. doi: 10.1038/s41598-021-83894-7

75. Nath SK, Han S, Kim-Howard X, Kelly JA, Viswanathan P, Gilkeson GS, et al. A Nonsynonymous Functional Variant in Integrin-Alpha(M) (Encoded by ITGAM) Is Associated With Systemic Lupus Erythematosus. Nat Genet (2008) 40:152-4. doi: 10.1038/ng.71

76. Deng Y, Tsao BP. Genetic Susceptibility to Systemic Lupus Erythematosus in the Genomic Era. Nat Rev Rheumatol (2010) 6:683-92. doi: 10.1038/ nrrheum.2010.176

77. Cheng RJ, Xiong AJ, Li YH, Pan SY, Zhang QP, Zhao Y, et al. Mesenchymal Stem Cells: Allogeneic MSC May Be Immunosuppressive But Autologous MSC Are Dysfunctional in Lupus Patients. Front Cell Dev Biol (2019) 7:285. doi: 10.3389/fcell.2019.00285

78. Zhao L, Chen S, Yang P, Cao H, Li L. The Role of Mesenchymal Stem Cells in Hematopoietic Stem Cell Transplantation: Prevention and Treatment of Graft-Versus-Host Disease. Stem Cell Res Ther (2019) 10:182. doi: 10.1186/ s13287-019-1287-9

79. Rombouts WJ, Ploemacher RE. Primary Murine MSC Show Highly Efficient Homing to the Bone Marrow But Lose Homing Ability Following Culture. Leukemia (2003) 17:160-70. doi: 10.1038/sj.leu.2402763

80. Bocelli-Tyndall C, Bracci L, Schaeren S, Feder-Mengus C, Barbero A, Tyndall A, et al. Human Bone Marrow Mesenchymal Stem Cells and Chondrocytes Promote and/or Suppress the In Vitro Proliferation of Lymphocytes Stimulated by Interleukins 2, 7 and 15. Ann Rheum Dis (2009) 68:1352-9. doi: 10.1136/ard.2008.094003

81. Wagner W, Horn P, Castoldi M, Diehlmann A, Bork S, Saffrich R, et al. Replicative Senescence of Mesenchymal Stem Cells: A Continuous and Organized Process. PloS One (2008) 3:e2213. doi: 10.1371/journal.pone. 0002213

82. Hladik D, Höfig I, Oestreicher U, Beckers J, Matjanovski M, Bao X, et al. Long-Term Culture of Mesenchymal Stem Cells Impairs ATM-Dependent Recognition of DNA Breaks and Increases Genetic Instability. Stem Cell Res Ther (2019) 10:218. doi: 10.1186/s13287-019-1334-6

83. Kurtz A. Mesenchymal Stem Cell Delivery Routes and Fate. Int J Stem Cells (2008) 1:1-7. doi: 10.15283/ijsc.2008.1.1.1

84. Baer PC, Sann J, Duecker RP, Ullrich E, Geiger H, Bader P, et al. Tracking of Infused Mesenchymal Stem Cells in Injured Pulmonary Tissue in AtmDeficient Mice. Cells (2020) 9:1444. doi: 10.3390/cells9061444

85. Ghosh D, McGrail DJ, Dawson MR. TGF- $\beta 1$ Pretreatment Improves the Function of Mesenchymal Stem Cells in the Wound Bed. Front Cell Dev Biol (2017) 5:28. doi: 10.3389/fcell.2017.00028

86. Umare V, Pradhan V, Nadkar M, Rajadhyaksha A, Patwardhan M, Ghosh KK, et al. Effect of Proinflammatory Cytokines (IL-6, TNF- $\alpha$, and IL-1 $\beta$ ) on Clinical Manifestations in Indian SLE Patients. Mediators Inflamm (2014) 2014:385297. doi: 10.1155/2014/385297

87. Acosta-Rodriguez EV, Napolitani G, Lanzavecchia A, Sallusto F. Interleukins 1beta and 6 But Not Transforming Growth Factor-Beta are Essential for the Differentiation of Interleukin 17-Producing Human $\mathrm{T}$ Helper Cells. Nat Immunol (2007) 8:942-9. doi: 10.1038/ni1496

88. Ding J, Su S, You T, Xia T, Lin X, Chen Z, et al. Serum Interleukin-6 Level is Correlated With the Disease Activity of Systemic Lupus Erythematosus: A Meta-Analysis. Clinics (Sao Paulo Brazil) (2020) 75:e1801. doi: 10.6061/ clinics/2020/e1801

89. Pricola KL, Kuhn NZ, Haleem-Smith H, Song Y, Tuan RS. Interleukin-6 Maintains Bone Marrow-Derived Mesenchymal Stem Cell Stemness by an ERK1/2-Dependent Mechanism. J Cell Biochem (2009) 108:577-88. doi: $10.1002 / j \mathrm{cb} .22289$

90. Geng L, Li X, Feng X, Zhang J, Wang D, Chen J, et al. Association of TNF- $\alpha$ With Impaired Migration Capacity of Mesenchymal Stem Cells in Patients
With Systemic Lupus Erythematosus. J Immunol Res (2014) 2014:169082. doi: $10.1155 / 2014 / 169082$

91. Sandborn WJ, Hanauer SB. Antitumor Necrosis Factor Therapy for Inflammatory Bowel Disease: A Review of Agents, Pharmacology, Clinical Results, and Safety. Inflammatory Bowel Dis (1999) 5:119-33. doi: 10.1097/ 00054725-199905000-00008

92. Zhu LJ, Yang X, Yu XQ. Anti-TNF-Alpha Therapies in Systemic Lupus Erythematosus. J Biomed Biotechnol (2010) 2010:465898. doi: 10.1155/2010/ 465898

93. Djouad F, Fritz V, Apparailly F, Louis-Plence P, Bony C, Sany J, et al. Reversal of the Immunosuppressive Properties of Mesenchymal Stem Cells by Tumor Necrosis Factor Alpha in Collagen-Induced Arthritis. Arthritis Rheumatism (2005) 52:1595-603. doi: 10.1002/art.21012

94. Dorraji SE, Hovd AK, Kanapathippillai P, Bakland G, Eilertsen G, Figenschau SL, et al. Mesenchymal Stem Cells and T Cells in the Formation of Tertiary Lymphoid Structures in Lupus Nephritis. Sci Rep (2018) 8:7861. doi: 10.1038/s41598-018-26265-Z

95. Dorronsoro A, Lang V, Ferrin I, Fernández-Rueda J, Zabaleta L, Pérez-Ruiz E, et al. Intracellular Role of IL-6 in Mesenchymal Stromal Cell Immunosuppression and Proliferation. Sci Rep (2020) 10:21853. doi: 10.1038/s41598-020-78864-4

96. Ocansey DKW, Pei B, Yan Y, Qian H, Zhang X, Xu W, et al. Improved Therapeutics of Modified Mesenchymal Stem Cells: An Update. J Trans Med (2020) 18:42. doi: 10.1186/s12967-020-02234-x

97. Chan MC, Kuok DI, Leung CY, Hui KP, Valkenburg SA, Lau EH, et al. Human Mesenchymal Stromal Cells Reduce Influenza A H5N1-Associated Acute Lung Injury In Vitro and In Vivo. Proc Natl Acad Sci USA (2016) 113:3621-6. doi: 10.1073/pnas.1601911113

98. Danielyan L, Schäfer R, von Ameln-Mayerhofer A, Bernhard F, Verleysdonk $\mathrm{S}$, Buadze $\mathrm{M}$, et al. Therapeutic Efficacy of Intranasally Delivered Mesenchymal Stem Cells in a Rat Model of Parkinson Disease. Rejuvenation Res (2011) 14:3-16. doi: 10.1089/rej.2010.1130

99. Xu J, Chen J, Li W, Lian W, Huang J, Lai B, et al. Additive Therapeutic Effects of Mesenchymal Stem Cells and IL-37 for Systemic Lupus Erythematosus. J Am Soc Nephrol (2020) 31:54-65. doi: 10.1681/ asn.2019050545

100. Fuenzalida P, Kurte M, Fernández-O'ryan C, Ibañez C, Gauthier-Abeliuk M, Vega-Letter AM, et al. Toll-Like Receptor 3 Pre-Conditioning Increases the Therapeutic Efficacy of Umbilical Cord Mesenchymal Stromal Cells in a Dextran Sulfate Sodium-Induced Colitis Model. Cytotherapy (2016) 18:63041. doi: 10.1016/j.jcyt.2016.02.002

101. Ankrum JA, Dastidar RG, Ong JF, Levy O, Karp JM. Performance-Enhanced Mesenchymal Stem Cells via Intracellular Delivery of Steroids. Sci Rep (2014) 4:4645. doi: 10.1038/srep04645

102. Saldaña L, Bensiamar F, Vallés G, Mancebo FJ, García-Rey E, Vilaboa N. Immunoregulatory Potential of Mesenchymal Stem Cells Following Activation by Macrophage-Derived Soluble Factors. Stem Cell Res Ther (2019) 10:58. doi: 10.1186/s13287-019-1156-6

103. Luk F, Carreras-Planella L, Korevaar SS, de Witte SFH, Borràs FE, Betjes $\mathrm{MGH}$, et al. Inflammatory Conditions Dictate the Effect of Mesenchymal Stem or Stromal Cells on B Cell Function. Front Immunol (2017) 8:1042. doi: 10.3389/fimmu.2017.01042

104. Fan H, Zhao G, Liu L, Liu F, Gong W, Liu X, et al. Pre-Treatment With IL-1 $\beta$ Enhances the Efficacy of MSC Transplantation in DSS-Induced Colitis. Cell Mol Immunol (2012) 9:473-81. doi: 10.1038/cmi.2012.40

105. Ren G, Zhang L, Zhao X, Xu G, Zhang Y, Roberts AI, et al. Mesenchymal Stem Cell-Mediated Immunosuppression Occurs via Concerted Action of Chemokines and Nitric Oxide. Cell Stem Cell (2008) 2:141-50. doi: 10.1016/ j.stem.2007.11.014

106. Zhao C, Pu Y, Zhang H, Hu X, Zhang R, He S, et al. IL10-Modified Human Mesenchymal Stem Cells Inhibit Pancreatic Cancer Growth Through Angiogenesis Inhibition. J Cancer (2020) 11:5345-52. doi: 10.7150/jca.38062

107. Liang X, Ding Y, Lin F, Zhang Y, Zhou X, Meng Q, et al. Overexpression of ERBB4 Rejuvenates Aged Mesenchymal Stem Cells and Enhances Angiogenesis via PI3K/AKT and MAPK/ERK Pathways. FASEB J Off Publ Fed Am Soc Exp Biol (2019) 33:4559-70. doi: 10.1096/fj.201801690R

108. Gu Z, Tan W, Feng G, Meng Y, Shen B, Liu H, et al. Wnt/ $\beta$-Catenin Signaling Mediates the Senescence of Bone Marrow-Mesenchymal Stem 
Cells From Systemic Lupus Erythematosus Patients Through the P53/P21 Pathway. Mol Cell Biochem (2014) 387:27-37. doi: 10.1007/s11010-0131866-5

109. Gu Z, Tan W, Ji J, Feng G, Meng Y, Da Z, et al. Rapamycin Reverses the Senescent Phenotype and Improves Immunoregulation of Mesenchymal Stem Cells From MRL/lpr Mice and Systemic Lupus Erythematosus Patients Through Inhibition of the mTOR Signaling Pathway. Aging (2016) 8:1102-14. doi: 10.18632/aging.100925

110. Zhang D, Chen Y, Xu X, Xiang H, Shi Y, Gao Y, et al. Autophagy Inhibits the Mesenchymal Stem Cell Aging Induced by D-Galactose Through ROS/JNK/ p38 Signalling. Clin Exp Pharmacol Physiol (2020) 47:466-77. doi: 10.1111/ 1440-1681.13207

111. Coutu DL, François M, Galipeau J. Inhibition of Cellular Senescence by Developmentally Regulated FGF Receptors in Mesenchymal Stem Cells. Blood (2011) 117:6801-12. doi: 10.1182/blood-2010-12-321539

112. Ren X, Hu B, Song M, Ding Z, Dang Y, Liu Z, et al. Maintenance of Nucleolar Homeostasis by CBX4 Alleviates Senescence and Osteoarthritis. Cell Rep (2019) 26:3643-3656.e3647. doi: 10.1016/j.celrep.2019.02.088

113. Lu N, LiX, Tan R, An J, Cai Z, Hu X, et al. HIF-1 $\alpha /$ Beclin1-Mediated Autophagy Is Involved in Neuroprotection Induced by Hypoxic Preconditioning. J Mol Neurosci MN (2018) 66:238-50. doi: 10.1007/s12031-018-1162-7

114. Jin HJ, Kwon JH, Kim M, Bae YK, Choi SJ, Oh W, et al. Downregulation of Melanoma Cell Adhesion Molecule (MCAM/CD146) Accelerates Cellular Senescence in Human Umbilical Cord Blood-Derived Mesenchymal Stem Cells. Stem Cells Transl Med (2016) 5:427-39. doi: 10.5966/sctm.2015-0109

115. Madsen SD, Jones SH, Tucker HA, Giler MK, Muller DC, Discher CT, et al. Survival of Aging CD264(+) and CD264(-) Populations of Human Bone Marrow Mesenchymal Stem Cells is Independent of Colony-Forming Efficiency. Biotechnol Bioeng (2020) 117:223-37. doi: 10.1002/bit.27195

116. Denu RA. SIRT3 Enhances Mesenchymal Stem Cell Longevity and Differentiation. Oxid Med Cell Longevity (2017) 2017:5841716. doi: $10.1155 / 2017 / 5841716$

117. Lee HJ, Choi B, Kim Y, Lee SE, Jin HJ, Lee HS, et al. The Upregulation of Toll-Like Receptor 3 via Autocrine IFN- $\beta$ Signaling Drives the Senescence of Human Umbilical Cord Blood-Derived Mesenchymal Stem Cells Through Jak1. Front Immunol (2019) 10:1659. doi: 10.3389/fimmu.2019.01659

118. Jiang HH, Ji LX, Li HY, Song QX, Bano Y, Chen L, et al. Combined Treatment With CCR1-Overexpressing Mesenchymal Stem Cells and CCL7 Enhances Engraftment and Promotes the Recovery of Simulated Birth Injury-Induced Stress Urinary Incontinence in Rats. Front Surg (2020) 7:40. doi: 10.3389/fsurg.2020.00040

119. Shen Z, Wang J, Huang Q, Shi Y, Wei Z, Zhang X, et al. Genetic Modification to Induce CXCR2 Overexpression in Mesenchymal Stem Cells Enhances Treatment Benefits in Radiation-Induced Oral Mucositis. Cell Death Dis (2018) 9:229. doi: 10.1038/s41419-018-0310-х

120. Zhang C, Zhu Y, Wang J, Hou L, Li W, An H. CXCR4-Overexpressing Umbilical Cord Mesenchymal Stem Cells Enhance Protection Against Radiation-Induced Lung Injury. Stem Cells Int (2019) 2019:2457082. doi: $10.1155 / 2019 / 2457082$

121. Cai R, Kawazoe N, Chen G. Influence of Surfaces Modified With Biomimetic Extracellular Matrices on Adhesion and Proliferation of Mesenchymal Stem
Cells and Osteosarcoma Cells. Colloids Surf B Biointerfaces (2015) 126:381-6. doi: 10.1016/j.colsurfb.2014.11.050

122. Kuddannaya S, Chuah YJ, Lee MH, Menon NV, Kang Y, Zhang Y. Surface Chemical Modification of Poly(Dimethylsiloxane) for the Enhanced Adhesion and Proliferation of Mesenchymal Stem Cells. ACS Appl Mater Interfaces (2013) 5:9777-84. doi: 10.1021/am402903e

123. Bai X, Xi J, Bi Y, Zhao X, Bing W, Meng X, et al. TNF- $\alpha$ Promotes Survival and Migration of MSCs Under Oxidative Stress via NF- $\kappa b$ Pathway to Attenuate Intimal Hyperplasia in Vein Grafts. J Cell Mol Med (2017) 21:2077-91. doi: 10.1111/jcmm.13131

124. Li X, He L, Yue Q, Lu J, Kang N, Xu X, et al. MiR-9-5p Promotes MSC Migration by Activating $\beta$-Catenin Signaling Pathway. Am J Physiol Cell Physiol (2017) 313:C80-c93. doi: 10.1152/ajpcell.00232.2016

125. Lee RH, Pulin AA, Seo MJ, Kota DJ, Ylostalo J, Larson BL, et al. Intravenous hMSCs Improve Myocardial Infarction in Mice Because Cells Embolized in Lung are Activated to Secrete the Anti-Inflammatory Protein TSG-6. Cell Stem Cell (2009) 5:54-63. doi: 10.1016/j.stem.2009.05.003

126. Kalimuthu S, Gangadaran P, Li XJ, Oh JM, Lee HW, Jeong SY, et al. In Vivo Therapeutic Potential of Mesenchymal Stem Cell-Derived Extracellular Vesicles With Optical Imaging Reporter in Tumor Mice Model. Sci Rep (2016) 6:30418. doi: 10.1038/srep30418

127. Lou G, Song X, Yang F, Wu S, Wang J, Chen Z, et al. Exosomes Derived From miR-122-Modified Adipose Tissue-Derived MSCs Increase Chemosensitivity of Hepatocellular Carcinoma. J Hematol Oncol (2015) 8:122. doi: 10.1186/s13045-015-0220-7

128. Yuan B, Pan S, Dong YQ, Zhang WW, He XD. Effect of Exosomes Derived From Mir-126-Modified Mesenchymal Stem Cells on the Repair Process of Spinal Cord Injury in Rats. Eur Rev Med Pharmacol Sci (2020) 24:4058. doi: 10.26355/eurrev_202004_20975

129. Ma J, Zhao Y, Sun L, Sun X, Zhao X, Sun X, et al. Exosomes Derived From Akt-Modified Human Umbilical Cord Mesenchymal Stem Cells Improve Cardiac Regeneration and Promote Angiogenesis via Activating PlateletDerived Growth Factor D. Stem Cells Transl Med (2017) 6:51-9. doi: $10.5966 /$ sctm.2016-0038

Conflict of Interest: The authors declare that the research was conducted in the absence of any commercial or financial relationships that could be construed as a potential conflict of interest.

Publisher's Note: All claims expressed in this article are solely those of the authors and do not necessarily represent those of their affiliated organizations, or those of the publisher, the editors and the reviewers. Any product that may be evaluated in this article, or claim that may be made by its manufacturer, is not guaranteed or endorsed by the publisher.

Copyright $\odot 2021 \mathrm{Li}$, Guo, Pan, Chen, Chen, Liu and Pan. This is an open-access article distributed under the terms of the Creative Commons Attribution License (CC BY). The use, distribution or reproduction in other forums is permitted, provided the original author(s) and the copyright owner(s) are credited and that the original publication in this journal is cited, in accordance with accepted academic practice. No use, distribution or reproduction is permitted which does not comply with these terms. 